\title{
Double-blind, parallel group, placebo-controlled study of Kjellmaniella crassifolia Miyabe (Gagome) in human: The potential of Gagome to activate the immune system
}

\author{
Jun Nishihira ${ }^{1 *}$, Mie Nishimura ${ }^{1}$, Miwako Sugawara ${ }^{2}$, and Masafumi Kudo ${ }^{2}$ \\ ${ }^{1}$ Department of Medical Management and Informatics, Hokkaido Information University, \\ Ebetsu, Hokkaido, 069-8585, Japan; ${ }^{2}$ Northern Advancement Center for Science \& Technology, \\ Sapporo 001-0021, Japan
}

*Corresponding author: M.D., Ph.D. Jun Nishihira, Department of Medical Management and Informatics, Hokkaido Information University, Nishi Nopporo 59-2, Ebetsu 069-8585 Hokkaido, Japan

Submission Date: September $9^{\text {th }}, 2017$, Acceptance Date: October $27^{\text {th }}$, 2017, Publication Date: October $31^{\text {st }}, 2017$

Citation: Nishihira J., Nishimura M., Sugawara M., Kudo M., Double-blind, parallel group, placebo-controlled study of Kjellmaniella crassifolia Miyabe (Gagome) in human: The potential of Gagome to activate the immune system. Functional Foods in Health and Disease 2017; 7(10): 758 -772. https://doi.org/10.31989/ffhd.v7i10.390

\section{ABSTRACT}

Background: Marine brown algae, Kjellmaniella crassifolia Miyabe (Gagome) is extensively harvested in Northern Japan and is known to help improve the immune system and prevent lifestyle diseases by its functional constituents, particularly the polysaccharide fucoidan. However, since most scientific findings come from animal studies, we examined its potential effectiveness in humans to raise immune functions, using small amounts of Gagome to avoid overconsumption of iodide.

Methods: We set up a double-blind, placebo-controlled clinical trial ( $\mathrm{n}=30$ subjects for Gagome consumption; $\mathrm{n}=30$ for placebo), in which 0.8 gram/day of Gagome containing 200 $\mathrm{mg}$ as dietary fiber (ca. $80 \mathrm{mg}$ as fucoidan) was ingested for 8 weeks. The primary end-point was natural killer (NK) cell activity while other immune-related biomarkers, such as immunoglobulins (IgM and IgA) and cytokines (IL-12 and IFN- $\gamma$ ) were secondary end-points.

Results: No adverse effects were observed during the course of the clinical trial. We found that 8-week daily Gagome intake raised NK cell activities for the group with a relatively higher 
baseline number of NK cells $(\mathrm{p}=0.03)$. We also demonstrated that Gagome intake exerted a tendency to stimulate IgA secretion. These results indicate the possibility that Gagome intake may potentiate host defense systems in human as seen in animal studies.

Conclusion: In this study, we used small amounts of Gagome ( $0.8 \mathrm{~g}$ daily) as an active test sample to avoid overconsumption of iodide, and found that this amount could enhance NK cell activities, particularly in the subclass with initially higher NK cell numbers. We also found an appreciable increment of IgA. With all of these facts, it seems that Gagome intake activates immune responses that contribute to the promotion of health through stimulation of the immune system.

Keywords: clinical trial, dietary fiber, fucoidan, Gagome, natural killer cells

\section{INTRODUCTION}

Kjellmaniella crassifolia Miyabe (Gagome) is a traditional seafood in Japan and is commonly consumed in daily life. Gagome, which is rich in polysaccharides, exhibits a wide variety of biological activities. These polysaccharides are popular as functional ingredients beneficial for health. There are three major functional constituents of Gagome: fucoidan, alginate, and laminarin [1]. In particular, the immunomodulatory functions of Gagome have been well demonstrated in a murine model, in which the phagocytic activity of peritoneal macrophages was enhanced by its oral administration [2].

Fucoidan, which is rich in polysaccharides, shows anti-allergic activity by suppression of Th2-dominant responses in mice [3] and prevented Helicobacter pyroli infection in Mongolian gerbils [4]. Fucoidan also exerted a prophylactic effect against enteral prion infection in mice [5], and an anti-tumor effect mediated by interferon (IFN)- $\gamma$-activated natural killer (NK) cells in mice [6]. Moreover, this particular polysaccharide was found to inhibit proliferation and induce apoptosis in human lymphoma cell lines [7].

It is of note that fucoidan isolated from Gagome is rich in more sulfated polysaccharides than those from other brown algae [8]. Most studies on fucoidan have been performed in mice and rats; therefore, little is known about its biological action in humans. In one human trial, fucoidan extracted from Gagome was administered for 4 weeks [9]. The production of Th1type cytokines (IL-12 and IFN- $\gamma$ ) was stimulated by Gagome-derived fucoidan, demonstrating that fucoidan is effective for stimulating the immune function in humans. These results of murine and human studies together support the theory that Gagome intake may be beneficial for our health promotion.

In addition to fucoidan, Gagome contains other bioactive compounds, such as alginate, an 
oligosaccharide that protects neural cells from apoptosis caused by oxidative stress [10], and stimulates cytokine secretion following intraperitoneal administration [11]. Alginate administration also decreased uptake of cholesterol and glucose uptake in overweight male subjects [12]. On the other hand, laminarin, another oligosaccharide contained in Gagome, lowered blood cholesterol [13] and facilitated wound healing [14].

Yan et al. demonstrated that Gagome extract modulates both intestinal and systemic immune responses [15]. The production of cytokines from antigen-specific $\mathrm{T}$ cells in lymph nodes and their proliferative response were significantly increased in association with an increase of memory $\mathrm{T}$ cells and antigen-specific IgA levels. Subsequently, Gagome is an effective immunomodulator and a potent adjuvant for both intestinal and systemic immune responses.

There are only a few reports of beneficial effects of Gagome in humans; therefore, we tried to elucidate the beneficial health effects, particularly in association with its immune function. Although Gagome has been promoted as a healthy food, excessive intake of Gagome may lead to deterioration of thyroid diseases due to the toxicity of iodide. We carefully determined the daily amount of Gagome in this study keeping in mind the risk of iodide overconsumption.

\section{SUBJECTS AND METHODS}

\section{Subjects}

We recruited healthy Japanese men and women between the ages of 35 and 65 years who were living in Ebetsu City and neighboring communities in Hokkaido, Japan. Volunteers who met any of the following criteria were excluded from participation in this study: 1) frequent intake (more than 5 days a week) of any type of seaweed, 2) any current relevant infections, 3 ) current use of immunomodulating drugs (antibiotics, immunosuppressive medicine, anti-inflammatory medicine), Chinese herbs, supplements (such as mushroom, yeast, or lactic acid bacteria preparations, or seaweed), 4) current use of any medicine for diarrhea or constipation, 5) history of significant illness, 6) pregnancy or lactation, 7) heavy smoking (more than 20 cigarettes/day) and/or excessive alcohol consumption (more than $20 \mathrm{~g}$ alcohol/day), and 8) history of severe allergic reaction to food. Participants were asked to terminate the intake of any foods or supplements containing Gagome.

The sample size was statistically determined to obtain a power of $80 \%$ with an alpha value if $0.05 \%$. It was calculated that a sample size of 60 (30 in the active test food group and 30 in the placebo food group) was required for an effect to be demonstrated. 


\section{Test Samples}

The Gagome used in this study was harvested from the southern coastal area of Hokkaido, Japan. Two types of test sample were prepared, one active Gagome sample and the other a nonactive placebo containing mostly dextrin rather than Gagome. The active sample (four capsules/day) contained $0.2 \mathrm{~g}$ of Gagome dietary fiber (corresponding to ca. $80 \mathrm{mg}$ fucoidan fiber) and other constituents (e.g., gelatin), while the placebo sample contained dextrin in place of Gagome. The active sample contained $3.0 \mathrm{mg}$ of iodide, the maximum recommended daily amount as defined in Japan [16]. Detailed nutrient compositions of the two samples are shown in Table 1.

Table 1. Profile of samples

\begin{tabular}{lcc} 
& Placebo & Gagome \\
\hline Calories (kcal) & 3.6 & 3.9 \\
Water $(\mathrm{g})$ & 0.1 & 0.1 \\
Proteins $(\mathrm{g})$ & 0.3 & 0.2 \\
Lipids $(\mathrm{g})$ & 0.0 & 0.0 \\
Carbohydrates $(\mathrm{g})$ & 0.7 & 0.7 \\
Ash (g) & 0.2 & 0.0 \\
Sodium (mg) & 0.0 & 0.4 \\
Dietary fiber $(\mathrm{g})$ & 0.2 & 0.0 \\
\hline
\end{tabular}

\section{Study Design}

The clinical trial was performed in a placebo-controlled, randomized, double-blind clinical trial. Subjects were randomly divided into two groups, an active Gagome group $(n=30)$ and a control (placebo) group ( $\mathrm{n}=30$ ) (Fig. 1). All of the subjects consumed $0.8 \mathrm{~g} /$ day (4 capsules/day) of either active Gagome or placebo for 8 weeks. The active capsules contained $200 \mathrm{mg}$ of fucoidan dietary fiber. We advised the volunteers not to change their daily lifestyle, including meals, exercise, and alcohol consumption during this study. A blood sample was collected at week 0 (W0) before intake of the first test sample, and at week 4 (W4) and week 8 (W8).

\section{Assessment of Immunogenicity}

Chromium-51 $\left({ }^{51} \mathrm{Cr}\right)$ release assays were used to measure NK cell activity (PerkinElmer, Waltham, MA) at weeks 0,4 , and 8 . Target cells were labeled with ${ }^{51} \mathrm{Cr}$, and the label was then released from the target cells by cytolysis. The supernatants from centrifugation could be counted directly by a gamma counter. All measurements were performed by the SRL clinical laboratory (Tokyo, Japan). 


\section{Serum Biochemical Measurement}

Hematological analyses were carried out for all types of blood cells [white blood cells (WBC), red blood cells (RBC), hemoglobin $(\mathrm{Hb})$, hematocrit $(\mathrm{Ht})$, and platelet count (Plt)]. Serum biochemical analyses were carried out on blood samples obtained at weeks 0,4 , and 8 , including total immunoglobulin $\mathrm{M}(\operatorname{Ig} \mathrm{M})$, total immunoglobulin $\mathrm{A}(\operatorname{Ig} \mathrm{A})$, liver function test [aspartate aminotransferase (AST), alanine aminotransferase (ALT), gamma glutamyl transpeptidase ( $\gamma$-GTP), alkaline phosphatase (ALP), and lactate dehydrogenase (LDH)], renal function test [blood urea nitrogen (BUN), creatinine (CRE), and ureic acid (UA)], serum lipids [total cholesterol (T-Cho), low density lipoprotein cholesterol (LDL-Cho), high density lipoprotein cholesterol (HDL-Cho), and Triglyceride (TG)], C-reactive protein (CRP), and blood glucose. These biomarkers were measured at a clinical laboratory testing center (Sapporo Clinical Laboratory Inc., Sapporo, Japan).

\section{Questionnaire}

All subjects were asked to report daily on any symptoms, fatigue levels, and defecation experienced during the study. For each symptom, levels of severity were set by degrees from 0 to $100 \mathrm{~mm}$ and poor to good, respectively (visual analogue scale, VAS). Total numbers were summed up for analysis, and incidence rates (\%) for each symptom were divided by the total incidence.

\section{Statistical Analysis}

All data were collected and analyzed independently of the investigators, who did not have access to the data or to its analysis. Only data analysts could access the data to perform statistical analyses. As for compliance, data were stored and maintained on secure servers, and backed up daily. Security updates were made in a timely manner regularly to ensure appropriate protection of the database. Between-group comparisons were assessed by Student's $t$-test. The interaction between the group and the period of consumption (group-by-time interaction) was analyzed using repeated-measures analysis of variance (ANOVA). Between-group comparisons of actual values and the amount of change from baseline were assessed by Student's $t$-test. Statistical analyses were performed using SPSS Statistic 20 (IBM, NY). A significance level of $p<0.05$ was considered to indicate significance.

\section{Ethics Committee}

Ethical clearance was obtained from the ethics committee of Hokkaido Information University before the study was initiated (certificate number: 2015-14). Informed consent was obtained 
after the contents of this study were explained to participants. Any undesirable events affecting a subject's health during the course of the study were defined as adverse events. If a subject asked to be released from the study, the protocol was immediately terminated for that subject. This study was conducted in accordance with the Declaration of Helsinki. This study was registered at the UMIN Clinical Trial Registry (UMIN000019451) on October 23, 2015.

\section{RESULTS}

\section{Baseline and demographic data}

Participants were recruited from among the residents of Ebetsu City (Hokkaido, Japan) and neighboring communities. The flow of participant involvement through the trial is shown in Figure 1. Subjects who provided consent $(n=117)$ were assessed for eligibility, and a total of 60 subjects were enrolled in this study. All enrolled subjects were randomized to one of the two intervention groups (Gagome group, $n=30$; placebo group, $n=30$ ). During the course of this study, 2 subjects discontinued the trial for personal reasons, due to starting of medication or relocation of residence. Thus, the number of evaluable subjects was 58 (Gagome group, $\mathrm{n}=29$; placebo group, $\mathrm{n}=29$ ).

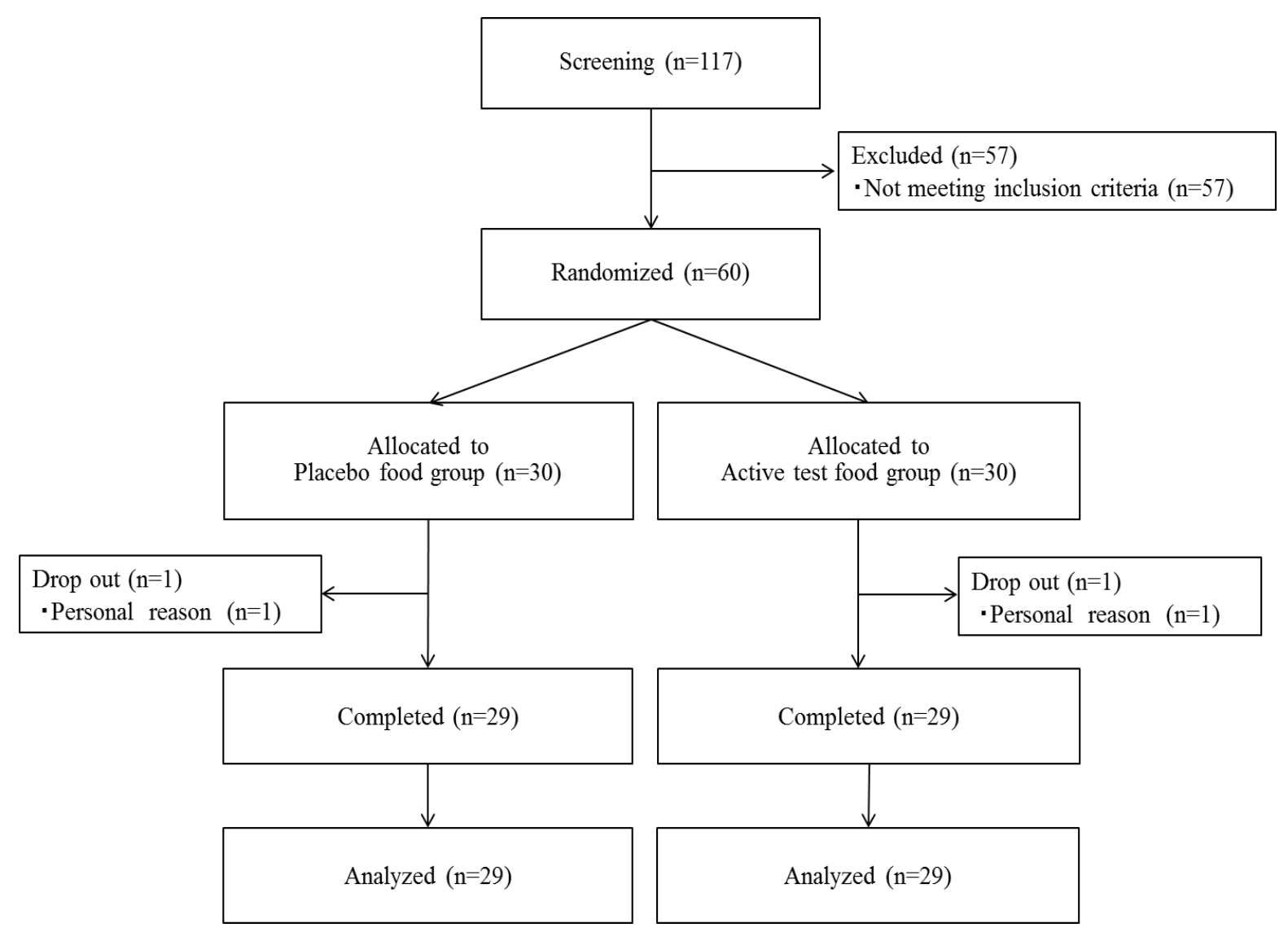

Figure 1. Flow diagram of the clinical trial. Values in parentheses indicate the number of participants. 
There were no significant differences between the Gagome and placebo groups with regard to gender, age, body mass index (BMI), natural killer cell activity, or intake rate of test foods (Table 2).

Table 2. Characteristics of subjects in the placebo and Gagome groups at the screening test.

\begin{tabular}{llll}
\hline Characteristic & Placebo & Gagome & $p$ \\
\hline Subjects, $n$ & 29 & 29 & - \\
Male, $n$ & 5 & 5 & 1.00 \\
Age, years & $51.69 \pm 8.23$ & $50.00 \pm 7.39$ & 0.41 \\
Body mass index, $\mathrm{kg} / \mathrm{m}^{2}$ & $20.66 \pm 3.15$ & $20.33 \pm 2.55$ & 0.66 \\
Natural killer cell activity, \% & $18.76 \pm 7.87$ & $19.41 \pm 7.31$ & 0.74 \\
Intake rate, \% & $99.13 \pm 2.06$ & $98.89 \pm 3.68$ & 0.54 \\
\hline
\end{tabular}

Statistical analysis was performed by Student's $t$-test for age, height, body weight, BMI, body fat percentage, and natural killer cell activity; by the chi-square test for gender; and by Mann-Whitney U test for intake rate. $\mathrm{n}$; number of subjects. Values shown are means \pm standard deviations (SDs).

\section{Serum biochemical data and vital signs}

We found no abnormal biochemical data for liver or renal functions, blood glucose, blood lipid, or CRP that would indicate any adverse effect in the Gagome or placebo group during the trial (Table 3). Values shown are means \pm standard deviations (SDs). Vital signs (blood pressure, pulse, and body temperature) raised no safety concerns during the trial (data not shown).

Table 3. Biochemical data.

\begin{tabular}{lllll} 
& & \multicolumn{1}{c}{ W0 } & \multicolumn{1}{c}{ W4 } & \multicolumn{1}{c}{ W8 } \\
\hline \hline WBC & Placebo & $4.78 \pm 1.26$ & $4.88 \pm 1.42$ & $4.95 \pm 1.55$ \\
$\left(\times 10^{3} / \mu \mathrm{l}\right)$ & Gagome & $4.83 \pm 1.05$ & $4.76 \pm 0.95$ & $4.82 \pm 0.95$ \\
\hline $\mathrm{RBC}$ & Placebo & $455.38 \pm 45.88$ & $457.10 \pm 45.88$ & $463.93 \pm 52.81$ \\
$\left(\times 10^{4} / \mu \mathrm{l}\right)$ & Gagome & $427.47 \pm 33.87$ & $432.39 \pm 32.96$ & $438.28 \pm 34.78$ \\
\hline $\mathrm{Hb}$ & Placebo & $13.64 \pm 1.64$ & $13.51 \pm 1.62$ & $13.76 \pm 1.76$ \\
$(\mathrm{~g} / \mathrm{dl})$ & Gagome & $13.26 \pm 0.99$ & $13.24 \pm 0.94$ & $13.52 \pm 0.96$ \\
\hline $\mathrm{Ht}$ & Placebo & $41.64 \pm 3.79$ & $41.29 \pm 4.12$ & $41.80 \pm 4.49$ \\
$(\%)$ & Gagome & $40.16 \pm 2.95$ & $40.55 \pm 2.70$ & $40.99 \pm 2.62$ \\
\hline $\mathrm{Plt}$ & Placebo & $24.83 \pm 6.76$ & $25.18 \pm 6.39$ & $26.10 \pm 6.49$ \\
$\left(\times 10^{4} / \mu \mathrm{l}\right)$ & Gagome & $23.63 \pm 5.47$ & $23.68 \pm 4.45$ & $24.10 \pm 5.57$ \\
\hline $\mathrm{AST}$ & Placebo & $20.38 \pm 4.21$ & $21.97 \pm 6.68$ & $21.69 \pm 5.46$
\end{tabular}




\begin{tabular}{|c|c|c|c|c|}
\hline & & W0 & W4 & W8 \\
\hline$(\mathrm{U} / 1)$ & Gagome & $21.83 \pm 4.69$ & $21.07 \pm 4.74$ & $22.79 \pm 5.66$ \\
\hline ALT & Placebo & $16.72 \pm 7.37$ & $17.52 \pm 8.75$ & $18.79 \pm 9.87$ \\
\hline$(\mathrm{U} / 1)$ & Gagome & $18.10 \pm 7.30$ & $16.71 \pm 5.37$ & $19.76 \pm 7.92$ \\
\hline$\gamma$-GTP & Placebo & $19.79 \pm 10.97$ & $20.24 \pm 11.74$ & $21.21 \pm 12.53$ \\
\hline$(\mathrm{U} / \mathrm{l})$ & Gagome & $22.63 \pm 12.58$ & $22.57 \pm 13.18$ & $23.41 \pm 13.27$ \\
\hline ALP & Placebo & $179.38 \pm 49.36$ & $181.79 \pm 50.93$ & $185.48 \pm 51.00$ \\
\hline (U/1) & Gagome & $191.90 \pm 49.30$ & $189.96 \pm 48.67$ & $192.41 \pm 49.28$ \\
\hline LDH & Placebo & $181.24 \pm 29.55$ & $188.34 \pm 27.94$ & $188.52 \pm 28.97$ \\
\hline$(\mathrm{U} / \mathrm{l})$ & Gagome & $184.93 \pm 22.20$ & $186.71 \pm 32.20$ & $187.34 \pm 26.55$ \\
\hline BUN & Placebo & $13.26 \pm 3.66$ & $13.20 \pm 3.57$ & $14.05 \pm 4.05$ \\
\hline$(\mathrm{mg} / \mathrm{dl})$ & Gagome & $12.95 \pm 3.28$ & $12.81 \pm 3.45$ & $13.71 \pm 2.95$ \\
\hline CRE & Placebo & $0.76 \pm 0.13$ & $0.74 \pm 0.12$ & $0.74 \pm 0.13$ \\
\hline$(\mathrm{mg} / \mathrm{dl})$ & Gagome & $0.75 \pm 0.13$ & $0.76 \pm 0.12$ & $0.75 \pm 0.11$ \\
\hline UA & Placebo & $4.38 \pm 0.86$ & $4.43 \pm 0.94$ & $4.48 \pm 0.95$ \\
\hline$(\mathrm{mg} / \mathrm{dl})$ & Gagome & $4.32 \pm 1.11$ & $4.38 \pm 1.22$ & $4.29 \pm 1.34$ \\
\hline T-Cho & Placebo & $208.03 \pm 34.16$ & $210.38 \pm 37.29$ & $213.79 \pm 33.45$ \\
\hline$(\mathrm{mg} / \mathrm{dl})$ & Gagome & $210.70 \pm 26.57$ & $213.82 \pm 24.11$ & $222.48 \pm 26.34$ \\
\hline LDL-Cho & Placebo & $123.10 \pm 30.72$ & $127.34 \pm 33.03$ & $128.76 \pm 29.43$ \\
\hline$(\mathrm{mg} / \mathrm{dl})$ & Gagome & $124.53 \pm 26.44$ & $128.68 \pm 26.10$ & $134.24 \pm 26.93$ \\
\hline HDL-Cho & Placebo & $76.62 \pm 18.97$ & $76.72 \pm 18.52$ & $75.52 \pm 18.12$ \\
\hline$(\mathrm{mg} / \mathrm{dl})$ & Gagome & $80.27 \pm 14.79$ & $79.79 \pm 16.96$ & $79.72 \pm 15.12$ \\
\hline TG & Placebo & $82.86 \pm 37.56$ & $73.17 \pm 30.98$ & $81.97 \pm 38.85$ \\
\hline$(\mathrm{mg} / \mathrm{dl})$ & Gagome & $72.40 \pm 27.53$ & $76.54 \pm 41.74$ & $78.69 \pm 37.49$ \\
\hline Glucose & Placebo & $86.17 \pm 9.24$ & $85.72 \pm 5.15$ & $85.00 \pm 5.83$ \\
\hline$(\mathrm{mg} / \mathrm{dl})$ & Gagome & $84.53 \pm 6.07$ & $84.75 \pm 7.73$ & $85.59 \pm 6.22$ \\
\hline $\mathrm{HbA1c}$ & Placebo & $5.19 \pm 0.25$ & $5.26 \pm 0.26$ & $5.37 \pm 0.27$ \\
\hline$(\%)$ & Gagome & $5.17 \pm 0.28$ & $5.19 \pm 0.29$ & $5.29 \pm 0.29$ \\
\hline $\mathrm{TSH}$ & Placebo & $1.70 \pm 0.87$ & $1.78 \pm 0.95$ & $1.81 \pm 1.06$ \\
\hline$(\mu \mathrm{IU} / \mathrm{ml})$ & Gagome & $1.81 \pm 1.21$ & $3.34 \pm 3.37$ & $3.05 \pm 3.22$ \\
\hline $\mathrm{T} 4$ & Placebo & $7.34 \pm 1.06$ & $7.00 \pm 0.79$ & $7.18 \pm 0.99$ \\
\hline$(\mu \mathrm{g} / \mathrm{dl})$ & Gagome & $6.97 \pm 0.84$ & $6.68 \pm 0.90$ & $6.66 \pm 0.91$ \\
\hline CRP & Placebo & $0.07 \pm 0.15$ & $0.05 \pm 0.05$ & $0.06 \pm 0.06$ \\
\hline$(\mathrm{mg} / \mathrm{dl})$ & Gagome & $0.03 \pm 0.03$ & $0.04 \pm 0.04$ & $0.03 \pm 0.02$ \\
\hline
\end{tabular}

Values shown are means \pm standard deviations (SDs). 


\section{NK cell activity}

As for immunological biomarkers, we measured NK cell activity and lymphocyte population analysis. The number of NK cells is critical for determining NK cell activity. Therefore, we carried out both overall and subclass analyses depending on baseline NK cell number for more detailed investigations. The average baseline NK cell number $\left(120 \times 10^{3} / \mu \mathrm{l}\right)$ was used as the cut-off between the low-NK-population and high-NK-population groups, respectively. As shown in Fig. 2a, we found no significant difference at either W4 or W8 in all subjects. In subclass analysis, we found marked increase of NK cell activity at W8 in the high-NKpopulation group, as shown in Fig. $2 b(p=0.03)$.

(a)

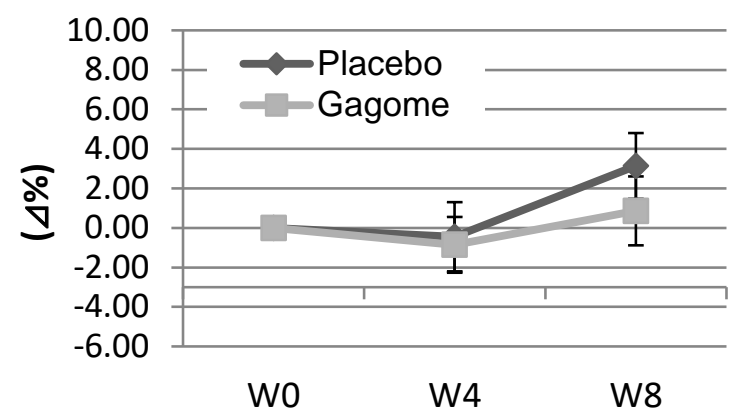

(b)

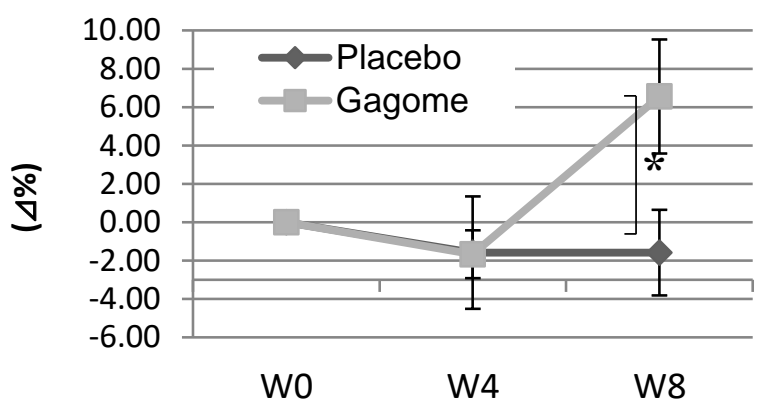

Figure 2. Differences in NK cell activity according to Gagome administration. (a) Difference in NK cell activity of all subjects. (b) Difference in NK cell activity in subjects whose baseline NK cell number was $120 \times 10^{3} / \mu$ or more (placebo, $n=12$; Gagome, $n=9$ ). ${ }^{*} p=0.03$

\section{Change of immunoglobulin profiles}

We examined the effect of Gagome on the production of immunoglobulins, IgM and IgA. These immunoglobulins IgM and IgA are known to be good biomarkers to detect early-phase change of immunoglobulin profiles and gut immunity, respectively. We found no difference in IgM changes between the two groups at W8 ( $p=0.93$ ) (Fig. 3a). On the other hand, an apparent increase of $\operatorname{IgA}$ was observed at both W4 $(\mathrm{p}=0.2)$ and W8 $(\mathrm{p}=0.21)$ in the Gagome group (Fig. $3 b)$.

(a)

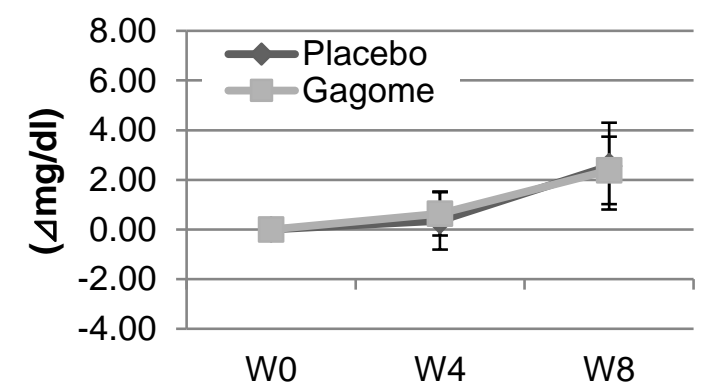

(b)

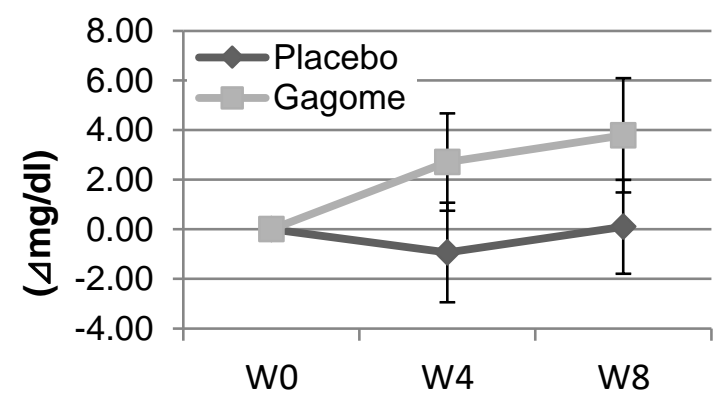

Figure 3. Changes of immunoglobulins. (a) IgM and (b) IgA levels in response to intake of Gagome and placebo. 


\section{Change of cytokines}

We examined Th1-type cytokine levels to examine the effect of Gagome on immune function. In contrast, we found no difference in IL-12 change between the two groups (Fig. 4a), we identified higher IFN- $\gamma$ production by Gagome than by placebo at W4, but not statistically significant ( $\mathrm{p}=0.27)$ (Fig. $4 b)$.

(a)

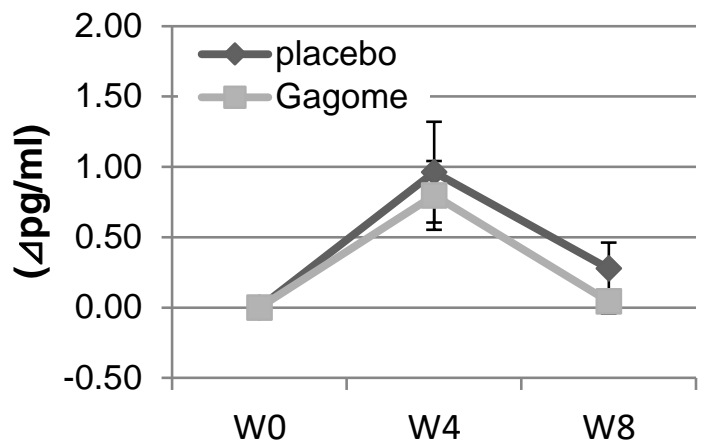

(b)

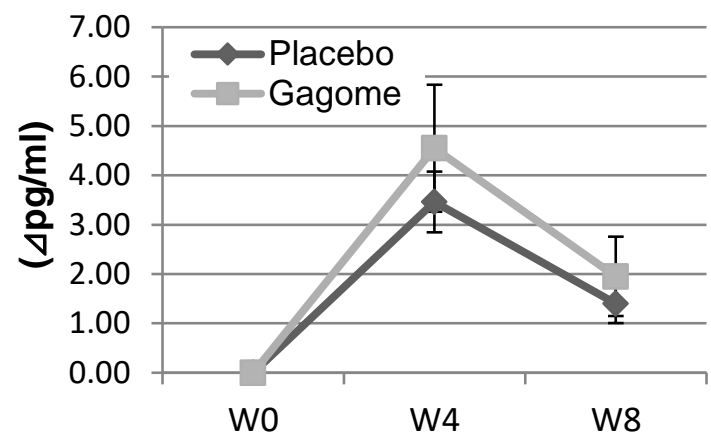

Figure 4. Changes of Th1-type cytokines. (a) IL-12 and (b) IFN- $\gamma$ levels in response to Gagome or placebo.

\section{Questionnaire of effect of Gagome on various subjects}

All subjects were asked to make a daily report of any symptoms regarding fatigability and defecation during the study. In between-group analysis of physical fatigability, the VAS value of change was improved neither W4 nor W8 between the placebo and Gagome groups ( $\mathrm{p}=0.9$ at W8) (Fig. 5a). On the other hand, we could identify a tendency of improvement by Gagome for mental fatigability, even though statistically not significant ( $\mathrm{p}=0.3$ at W8) (Fig. 5b). As for defecation, we expected this effect due to the presence of extra dietary fiber but observed little difference compared with the placebo (data not shown).

(a)

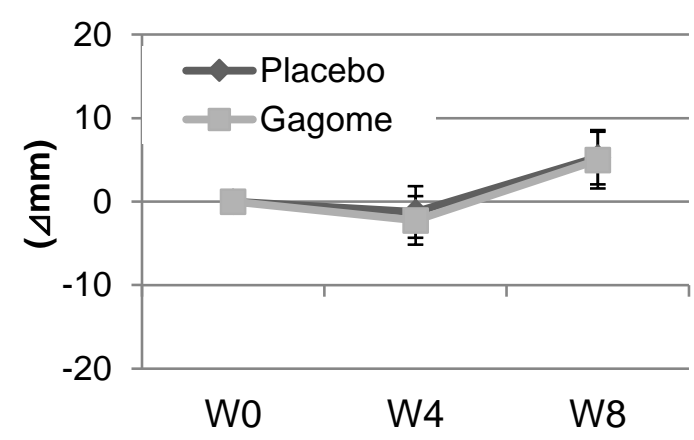

(b)

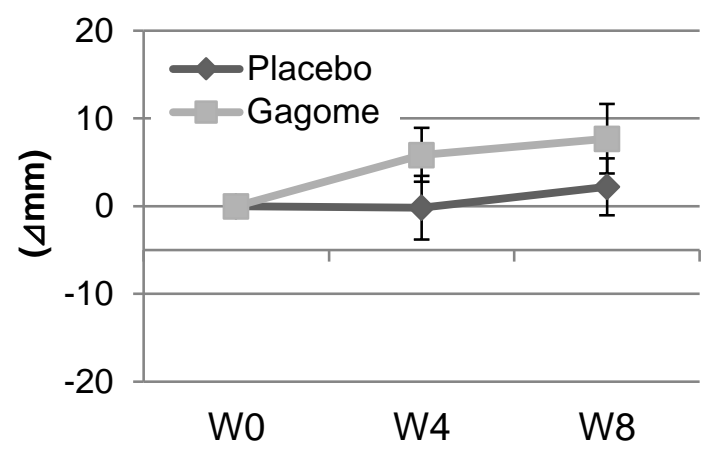

Figure 5. VAS study of Gagome on physical and mental fatigabilities in response to Gagome or placebo. (a) Change of physical fatigability (b) Change of mental fatigability. 


\section{DISCUSSION}

It is generally accepted that polysaccharides from various natural sources such as mushrooms and seaweed are potent immune-boosting natural compounds useful for health promotion. One report showed that intraperitoneally and orally administered $\beta-(1,3-1,6)$ glucan isolated from Aureobastidium pullulans prevented the reduction of the number of NK- and IFN- $\gamma$-positive cells induced by implantation of tumor cells [17]. This suggested that the anti-tumor effect of the $\beta$-glucan was due to the enhancement of intestinal immune functions by way of NK cell activation through IL-12 and IFN- $\gamma$ production.

Seaweeds such as Gagome and Mekabu are rich in bioactive polysaccharides. Animal studies on the use of Gagome and other seaweeds have been extensively performed, focusing on the improvement of lifestyle diseases. In particular, brown algae is a group of traditional seaweeds that have long been consumed in Japan and other East Asian countries. Recently, there has been increasing interest in the use of brown algae as health foods as they contain several polysaccharides, particularly fucoidan, from the point of view of metal chelation and immunomodulation $[1,2]$.

To the best of our knowledge, human studies on Gagome are limited. Thus, it would be worthwhile if we could prove the health effects of Gagome in humans. Concerning this issue, a research group reported the efficacy of fucoidan extracted from Gagome in healthy adults [9]. In a randomized, double-blind, placebo-controlled study, 30 subjects who consumed extracted Gagome dietary fiber ( $200 \mathrm{mg} /$ day) or placebo for 4 weeks were enrolled. Intake of this amount of fucoidan for 4 weeks significantly suppressed the decrease in production of the Th1-type cell-derived cytokines IFN- $\gamma$ and IL-12. They concluded that Gagome-derived extracted fucoidan (200 mg/day) was a useful and safe food ingredient to support immune function.

On the other hand, in this study Gagome overall was less effective than expected (Fig. 2). We could only demonstrate a significant elevation of NK cell activities by Gagome in the group with higher baseline number of NK cells. In this study, we used a much lower amount of Gagome fucoidan (ca. $80 \mathrm{mg} /$ day) than in the previously mentioned study. We could not set the optimal and sufficient dose of Gagome fucoidan (200 mg/day) used in the previous study [9] because of the upper limit of iodine intake recommended by Food Safety in Japan [16]. In the end, we had to use a relatively lower amount of Gagome, which was not enough to elicit the immune response of NK cell activity.

Concerning elevation of NK cell activity in response to fucoidan, it is hypothesized that IL-12 induces the differentiation of Th-1 cells, resulting in IFN- $\gamma$ production followed by NK cell activation. In view of signal transduction, there was no clear enhancement of either IL-12 or IFN- $\gamma$ production (Fig. 4). As for potential factors affecting the outcomes, we considered the 
potential that NK cell activities of participating subjects were as a total higher. Likewise, we sometimes experienced that increase of NK cell activities in response to functional foods are not well observed for groups with higher baseline NK cell activities; it hinders clear detection of the effectiveness of immune stimulation. Nevertheless, the data obtained by the current study suggests the possibility that Gagome intake at least in part stimulates the Th-1 type pathway for NK cell activation. In order to further investigate this possibility, it would be worthwhile to perform these experiments by recruiting subjects with initially low NK cell activity. Moreover, it may be necessary to process Gagome fucoidan dietary fiber to contain a lower amount of iodide, which would make it possible to increase the dosage. In those conditions, we may be able to clearly prove that Gagome intake plays an important role in the stimulation of immune mechanisms.

The luminal environment of the intestines affecting the systemic immune response is increasingly recognized as of great importance [18-20]. Mucosal immunity including the function of microbiota is the key to understanding the health aspects of many foods. As major luminal contents in the intestines, components of a normal diet should stimulate innate immune cells, providing a link between food components and specific immunity, where IgA plays an essential role. Yan et al demonstrated that Gagome markedly enhanced cytokine production and intestinal antigen-specific IgA antibody after systemic immunization [15]. We demonstrated that IgA levels were raised in response to Gagome intake. Another report demonstrated that highly viscous polysaccharide extract from Gagome stimulated the secretion of IgA in spleen cells and Peyer's patch cells in mice [2]. The result of this animal experiment is consistent with our current results, as shown in Figure 3.

IgA is the main immunoglobulin of the mucosal immune system [21]. In particular, it provides an anti-infectious mechanism by neutralizing pathogens and their toxins, preventing pathogens from binding to mucosal surfaces and enhancing the protective effects of other immune factors [2]. Therefore, it seems administration of Gagome would be beneficial in preventing intestinal infectious diseases. From these results, it is conceivable that Gagome dietary supplementation could effectively enhance both intestinal and the whole body health.

Lastly, we demonstrated that the continuous intake of Gagome may be beneficial for boosting the immune system and may be recommended for subjects who are poor immune responders due to aging or chronic diseases. Furthermore, the current study provided some evidence that Gagome intake would activate adaptive and innate immune responses. As for other functional materials other than fucoidan, alginate can protect cells from apoptosis by inducing the secretion of specific cytokines and also regulating the uptake of cholesterol and glucose [10-12]. Laminarin, on the other hand, has activities to lower blood cholesterol, in 
addition to facilitating wound healing $[13,14]$. Therefore, the structurally various types of $\beta$ glucan contained within these functional materials are considered to play specific roles in the immune responses [22]. We also discovered a new aspect of Gagome. From the results of questionnaires, we found some evidence suggesting that Gagome may be effective for the improvement of mental stress or mental "fatigability" (Fig. 5). Microbiota are widely involved in the intestine-brain axis; this aspect of Gagome needs further investigation. In conclusion, based on the findings demonstrated in this study, we expect that Gagome dietary supplementation potentiates the host defense system and protects the human body from various kind of diseases related to immune systems.

List of Abbreviations: NK, natural killer; IL-12 and IFN- $\gamma$, cytokines; $51 \mathrm{Cr}$, Chromium-51; WBC, white blood cells; RBC, red blood cells;Hb, hemoglobin; Ht, hemocrit; Plt, platelet count; IgM, total immunoglobulin $\mathrm{M}$; IgA, total immunoglobulin A; AST, aspartate aminotransferase; ALT, alanine aminotransferase; $\gamma$-GTP, renal transpeptidase; ALP, alkaline phosphatase; LDH, lactate dehydrogenase; BUN, blood urea nitrogen; CRE, creatinine; UA, ureic acid; T-Cho, total cholesterol; LDL-Cho, low density lipoprotein cholesterol; HDL-Cho, high density lipoprotein cholesterol; TG, Triglyceride; CRP, C-reactive protein; VAS, visual analogue scale; ANOVA, analysis of variance; BMI, body mass index; SD, standard deviation.

Competing Interests: The authors have no potential conflicts of interest to report.

Authors' Contributions: All the authors contributed to this study

Acknowledgements and Funding: This work was supported by a grant from the Research Project on the Development of Functional Foods Produced in Hokkaido (Hokkaido, Japan).

\section{REFERENCES}

1. Davis TA, Volesky B, Mucci A: A review of the biochemistry of heavy metal biosorption by brown alagae. Water Res 2003, 37: 4311-4330.

2. Katayama S, Nishio T, Kishimura H, Saeki H: Immunomodulatory properties of highly viscous polysaccharide extract from the Gagome alga (Kjellmaniella crassifolia). Plant Foods Hum Nutr 2012, 67: 76-81.

3. Maruyama H, Tamauchi H, Hashimoto M, Nakano T: Suppressio of Th2 immune responses by mekabu fuoidan from Undaria pinnatifida sporophyylls. Int Arch Allergy Immunol 2005, 137: 289-294.

4. Shibata H, limuro M, Uchiya N, Kawamori T, Nagaoka M, Ueyama S, Hashimoto 
S, Yokokura T, Sugimura T, Wakabayashi K Preventive effects of Cladosiphon fucoidan against Helicobactor pylori infection in Mongolian gerbils. Helicobacter 2003, 8: 59-65.

5. Doh-Ura K, Kuge T, Uomoto M, Nishizawa K, Kawasaki Y, Iha M: Prophylactic effect of dietary seaweed fucoidan against eternal prion infection. Antimicrob. Agents Chemother 2007, 51: 2274-2277.

6. Maruyama H, Tamauchi H, Hashimoto M, Nakano T: Antitumor activity and immune response of Mekabu fucoidan extracted from Sporophyll of Undaria pinnatifida. In Vivo 2003, 17: 245-249.

7. Aisa Y, Miyakawa Y, Nakazato T, Shibata H, Saito K, Ikeda Y, Kizaki M: Fucoidan induces apoptosis of human HS-sultan cells accompanied by activation of caspase3 and down-regulation of ERK pathways. Am J Hematol 2005, 78: 7-14.

8. Sakai T, Koto I: Structure and biological activities of marine alagal fucoidans and their oligosaccharides. Bioscience and Industry (in Japanese) 2008, 60: 377-380.

9. Ohnogi H, Naito Y, Higashimura Y, Uno K, Yoshikawa T: Immune efficacy and safety of fucoidan extract from Gagome Kombu (Kjellmaniella crassifolia) in healthy Japanese subjects. JJCAM 2015, 12: 87-93.

10. Tusi SK, Khalaj L, Ashabi G, Kiaei M, Khodagholi F: Alginate oligosaccharide protects against endoplasmic reticulum- and mitochondrial-mediated apoptotic cell death and oxidative stress. Biomaterials 2011, 32: 5438-5458.

11. Yamamoto Y, Kurachi M, Yamaguchi K, Oda T: Stimulation of multiple cytokine production in mice by alginate oligosaccharides following intraperitoneal administration. Carbohydr Res 2007, 342: 1133-1137.

12. Paxman JR, Richardson JC, Dettmar PW, Corfe BM: Alginate reduces the increased uptake of cholesterol and glucose in overweight male subjects: a pilot study. Nutr Res 2008, 28: 501-505.

13. Keenan JM, Goulson M, Shamliyan T, Knutson N, Kolberg L, Curry L: The effects of concentrated barley b-glucan on blood lipid in population of hyercholesterolemic men and women. Br J Nutr 2007, 97:1162-1168.

14. Berdal M, Appelbom HI, Eikrem JH, Lund A, Zykova S, Busund LT, Seljelid R, Jenssen T: Aminated beta-1,3-D-glucan improves wound healing in diabetic $\mathrm{db} / \mathrm{db}$ mice. Wound Repair Regen 2007, 15: 825-832.

15. Yan H, Kakuta S, Nishihira K, Sugi M, Adachi Y, Ohno N, Iwakura Y, Tsuji NM: Kjellmaniella crassifolia Miyabi (Gagome) extract modulates intestinal and systemic immune response. Biosci Biotechnol Biochim 2001, 75: 2178-2183. 
16. Ministry of Health, Labour and Wellfare, Japan. Overview of Dietary Reference Intakes for Japanese; 2015: 39. [http://www.mhlw.go.jp/file/06-Seisakujouhou10900000-Kenkoukyoku/Overview.pdf]

17. Kimura Y, Sumiyoshi M, Suzuki T, Sakanaka M: Anti-tumor and antimetastatic activity of a novel water soluble low molecular weight $\beta$-1,3-D-Glucan (branch $\beta$ 1,6) isolated from aureobacsidium 1A1 strain black yeast. Anticancer Res 2006: 26:4131-4141.

18. Mazmanian SK, Round JL, Kasper DL: A microbial symbiosis factor prevents intestinal inflammatory disease. Nature 2008, 453: 620-625.

19. Round JL, Mazmanian SK: Inducible Foxp3+ regulatory T-cell development by a commensal bacterium of the intestinal microbiota. Proc Natl Acad Sci USA 2010, 107: 12204-12209.

20. Lee YK, Menezes JS, Umesaki Y, Mazmanian SK: Proinflammatory T-cell responses to gut microbiota promote experimental autoimmune encephalomyelitis. Proc Natl Acad Sci USA 2011, 108: 4615-4622.

21. Fagarasan S, Honjo T: Intestinal IgA synthesis: regulation of front-line body defences. Nat Rev Immunol 2003, 3: 63-72.

22. Luhm J, Langenkamp U, Hensel J, Frohn C, Brand JM, Hennig H, Rink L, Koritke P, Wittkopf N, Williams DL, Mueller A: BMC Immunol 2006, 7: 5. https://doi.org/10.1186/1471-2172-7-5. 